\title{
Equity in Swedish Health Care Reconsidered: New Results based on the Finite Mixture Model
}

\author{
Ulf-G. Gerdtham*and Pravin K. Trivedi ${ }^{\dagger}$ \\ Stockholm School of Economics \\ This version: March 2000
}

\begin{abstract}
This paper reconsiders the equity issue in Swedish health care utilisation previously analyzed by Gerdtham (Health Economics 6, 303-319, 1997) within the framework of the standard two-part model. Departing from the user/nonuser distinction, we use the more flexible framework of the finite mixture model that distinguishes between frequent/infrequent users. Our empirical results indicate that the finite mixture model fits the data better than the two-part model. The results indicate that income increases use among infrequent users in both physician and hospital care but that there is no such income effect among frequent users.

Key words: Equity, Health Care, Count Data, Latent Class Models, Finite Mixture Models.

JEL-classification: C20; C25; C52; I10; I18.
\end{abstract}

*Address for correspondence: Ulf-G. Gerdtham, Centre for Health Economics, Stockholm School of Economics, Box 6501, SE-113 83 Stockholm, Sweden. Tel: +46-8-7369283. Fax: +46-8-302115. E-mail: heug@hhs.se.

${ }^{\dagger}$ Department of Economics, Indiana University, Wylie Hall, Bloomington, IN 47405, U.S.A. 


\section{Introduction}

The important issue of income-related inequity in health care utilisation has received increasing attention in economics in recent years (O'Donnell and Propper 1991; Wagstaff et al. 1991; van Doorslaer and Wagstaff 1992; Hamilton et al. 1997; Gerdtham et al. 1997; van Doorslaer et al., forthcoming; see also Wagstaff and van Doorslaer, forthcoming). Empirical work on this topic typically deals with the horizontal version of the principle of distribution according to need, i.e., that individuals in equal need (in terms of morbidity) should be treated the same (in terms of health care utilisation), regardless of social status (in terms of income).

Two different approaches have been used to study equity issues in health care. One approach ranks individuals by income and then compares the cumulative proportion of actual utilisation (controlling for morbidity) across income groups. This also uses regression analysis to test for significant income effects on health care utilisation, i.e. controlling for morbidity, the additional explanatory power provided by inclusion of income and interactions between income and morbidity are examined (van Doorslaer and Wagstaff 1992). ${ }^{1}$ Such inequity analysis de-

\footnotetext{
${ }^{1} \mathrm{~A}$ variant of this approach ranks individuals by income and compares the cumulative proportion of actual utilisation with the cumulative proportion of the predicted utilisation across income groups (indirect need standardization); see van Doorslaer et al., forthcoming). The standardized values are computed as the predicted values saved from a regression equation in which health care utilisation is regressed on a vector of morbidity variables, age, and gender. The extent of horizontal inequity is measured as the difference between the concentration index for actual health care utilisation and the concentration index for predicted health care utilisation. Since it is possible to estimate standard errors for concentration indices as shown by Kakwani et al. (1997), it is also possible to test for the hypothesis of no-inequity by testing the null of
} 
scribes how standardized health care utilisation varies with income. However, it is also important to establish why such inequity in health care utilisation exists.

An alternative approach is based on empirical literature on the demand for health care (Gerdtham, 1997). Apart from age, gender, health and income, such models may also include as covariates prices of health care, insurance status, environmental factors, and the level of education (Grossman, 1972; Manning et al., 1987; Keeler et al., 1988; Grottendorst, 1995; Pohlmeier and Ulrich, 1995 and Deb and Trivedi, 1997). Using this strategy, the hypothesis of zero inequity is rejected if, controlling for need, one finds evidence that higher income, education, insurance status, etc. are associated with higher (or lower) usage of health care.

Gerdtham (1997) applied the latter strategy to cross-section data from Sweden. This study analyzed two variables, physician visits and hospital care weeks, respectively, using count data version of two-part (hurdle) model (Mullahy, 1986). He found some evidence in support of the horizontal inequity hypothesis within the framework of a two-part model.

In this paper we critically re-evaluate robustness of the previous conclusions regarding the horizontal inequity hypothesis by a new analysis of the data used in Gerdtham (1997). This analysis uses the finite mixture framework that is an alternative to the popular two-part model and appears to provide a better fit to the data. Section 2 defines the competing frameworks and summarizes their properties. Section 3 presents the results with emphasis on the role of income and related sociodemographic variables. Section 4 provides discussion and conclusion. no difference between the above mentioned concentration indexes. 


\section{Estimation methods}

In contrast to the earlier work which uses the well-known two-part model of health care utilisation, the present analysis is within the framework of finite mixture (or latent class) models that are typically more flexible than previously considered alternatives.

This paper will compare the two-part model with the finite mixture model by using several measures of model performance and model fit, including Akaike Information Criterion (AIC), Bayesian Information Criterion (BIC). To permit a comparison with previous results we use a nationally representative sample in Gerdtham (1997), the 1991 Level of Living Survey (LNU). The details of the Swedish health system and of the sample are given in Gerdtham (1997). ${ }^{2}$

\subsection{The two-part model}

In the two-part framework a distinction is made between nonusers and users of health care. The nonusers are those who are observed to register zero utilisation in the observation period. Users are those who register positive utilisation. Within the two-part model framework, the first part models the split between non-users (zeros) and users (positives) based on some binary outcome model. The second part (of the two-part model) models the utilisation of those who register positive utilisation, using a truncated count model. In the paper by Gerdtham, a logit model was used for the first part and a truncated-at-zero negative binomial for

\footnotetext{
${ }^{2}$ The total sample consists of 7,856 individuals, between the ages 18-76 years in 1991. After correcting for missing values, the sample was reduced to 5,011 individuals in 1991 . The survey contains data on morbidity, health care utilisation, and different socioeconomic variables.
} 
the second part (TPNB2).

The first part involves only binary information, that is,

$$
\operatorname{Pr}_{h}\left(y_{i}=0 \mid x_{i}\right)=\left(\frac{\psi_{h, i}}{\lambda_{h, i}+\psi_{h, i}}\right)^{\psi_{h, i}}
$$

where the subscript $h$ denotes parameters associated with the "hurdle distribution". The second part specifies the distribution of utilisation, given some use, as a truncated negative binomial distribution given by

$$
f\left(y_{i} \mid x_{i}, y_{i}>0\right)=\frac{\Gamma\left(y_{i}+\psi_{i}\right)}{\Gamma\left(\psi_{i}\right) \Gamma\left(y_{i}+1\right)}\left[\left(\frac{\lambda_{i}+\psi_{i}}{\psi_{i}}\right)^{\psi_{i}}-1\right]^{-1}\left(\frac{\lambda_{i}}{\lambda_{i}+\psi_{i}}\right)^{y_{i}} .
$$

The two-part model (TPM) has generally been found to provide a good fit if the sample data have a high frequency of zero observations ("non-users"), either on frequency of usage or medical care expenditure. Some writers have linked the two-part model to the principal-agent model in which the observed outcomes reflect a two-part decision making process; the first part relates to the patient's decision to contact the physician ("contact decision"), and the second part ("frequency decision") to the decision regarding repeat visits and/or referrals, that are assumed to be determined largely by the preferences of the physician. Although this argument adds credibility to the two-part model framework, this link is somewhat tenuous, as several papers have pointed (Pohlmeier and Ulrich, 1995; Gerdtham, 1997; Deb and Trivedi, 1999). In order to make a direct link between the two-part model framework and the principal agent framework, it is necessary to assume that the available data pertain to complete episodes of illness so that a clear distinction between the "contact decision" and "frequency decision" can be made. In cross section data it may be more realistic to assume that the data are a mixture of unknown number of complete and incomplete spells. 
Gerdtham rejected the null hypothesis of zero inequity because socioeconomic factors were found to have had significant effects on utilisation; e.g., income and size of community of residence. The probability of usage of physician visits tended to be positively associated with income (at a decreasing rate), but income was not a significant factor in explaining the frequency of physician visits. Gerdtham also re-estimated the model of physician visits separately for healthy (reporting good health) and unhealthy (reporting fair or bad health) people. The results of these sub-sample estimations indicated that the effect of income (all four income quintile dummies) was positive and significant in explaining the health care usage for the unhealthy, but not for the healthy people, and never significant in explaining the frequency of use. He further found that the size of community of residence has a positive significant effect on the frequency of physician visits but not on the probability of any physician visit.

\subsection{The finite mixture model}

A finite mixture density, with constant mixing probabilities $\pi_{j}$, for the random variables $y$ is defined by:

$$
f(y \mid x, \theta)=\sum_{j=1}^{C} \pi_{j} f_{j}(y \mid x, \theta),
$$

an additive mixture of $\mathrm{C}$ distinct latent classes or subpopulations, with unknown mixing proportions $\pi_{1}, \ldots, \pi_{C}$, where $\sum_{j=1}^{C} \pi_{j}>0(j=1, \ldots C) \ldots$ If $C$ is taken as a known constant, usually some small value like 2 or 3 , then one can use the maximum likelihood method. When $C$ is unknown, its value is chosen from a subset of alternatives using an information criterion for model selection. In its full generality this formulation involves $(C(\operatorname{dim}(\boldsymbol{\theta}))+(C-1))$ parameters. 
Once estimated, the parameters yield the full distribution of $y$ (and its moments) for each subpopulation. Throughout this paper we use a two-component model $(C=2)$, this value having been chosen on the basis of model selection criteria. We note that there is an extensive discussion in the literature on tests of hypothesis, especially the likelihood ratio test, regarding the number of components $C$ (see Cameron and Trivedi (1998), chapter 4.8). The issue is technically complicated because the hypothesis involves a boundary parameter. Our approach is based on model selection and not hypothesis testing. The $f(\cdot)$ distribution is negative binomial. Therefore we use the acronym FMNB2 to refer to this particular finite mixture.

Unlike the popular two-part model that distinguishes between users/nonusers, the finite mixture model distinguishes between frequent/infrequent users (Deb and Trivedi, 1999). The frequent/infrequent user distinction applies to latent classes whereas the healthy/unhealthy distinction is based on observable health indicators that may be partial proxies for whatever latent characteristics split the population into frequent/infrequent user classes. The relatively greater flexibility of the finite mixture model is a consequence of the feature that it assumes that the data are drawn from several distinct but latent sub-populations whose parameters can be estimated; hence the terminology latent class or finite mixture. That is, it accommodates discrete heterogeneity on the top of continuous heterogeneity that can be captured through a sufficiently flexible choice of $f(\cdot)$. For example, one may use a finite mixture of negative binomial components. The formulation permits mixing with respect to both zeros and positives. In principle it can provide a better approximation to any true, but unknown, probability density 
(Laird, 1978; Heckman and Singer, 1984). ${ }^{3}$

\section{Results}

Both the finite mixture and the two-part models are estimated using (pseudo) maximum likelihood. That is, the models are estimated by maximum likelihood but, unlike Gerdtham (1997), the standard errors and 't-ratios' of coefficients are estimated using the robust ("sandwich") variance formula (Cameron and Trivedi, 1998, p. 31). This is desirable because of the possibility of a misspecification of the unknown density.

Three criteria are used to compare models in-sample. These include two traditional model selection criteria based on penalized likelihood, Akaike Information Criterion, $A I C$, and Bayesian Information Criterion, BIC. Models with smaller values of the $A I C=-2 \ln L+2 K$ and $B I C=-2 \ln L+K \ln (N)$, where $\ln L$ is the maximized log likelihood, $K$ is the number of parameters in the model and $N$ is the sample size, are preferred.

Our results are reported in two parts. The first part involves estimation and evaluation of the TPNB2 and of the FMNB2. The second part summarizes the estimated socioeconomic effects of the preferred model. In Table 1 definitions and summary statistics are given for the variables used in the regression analysis. Tables 2 and 3 present the estimation results with the covariates included for number of physician visits and hospital care weeks, respectively. In both tables, the first

\footnotetext{
${ }^{3}$ As noted in Deb and Trivedi (1997), the two-part model is also a finite mixture from a statistical point of view since it combines zeros from a binomial density with the positives from a zero-truncated density, but it is more restrictive as compared with the finite mixture model.
} 
and second columns gives the ML estimates for the TPNB2 model consisting of the binary logit part that models the nonuser/user outcome, and the second stage conditional part that models the frequency distribution for the users using the truncated-at-zero negbin2 model. The third and fourth columns display the ML estimates of the FMNB2 model; those in column 3 correspond to infrequent (or low mean) users and those in column 4 correspond to those who are frequent (or high-mean) users.

The maximized value of the likelihood is higher for the 2-component mixture model in both cases, but the margin of improvement is greater in the case of doctor visits than hospital weeks. The penalized log-likelihood criteria, AIC and BIC, clearly favor the 2-component mixture as a better specification. The first panel in Table 4 compares the empirical and fitted relative frequencies for the two models. In this regard both models do a good job of capturing the basic features of the data. Our ability to discriminate between the models on this criterion is therefore limited.

The second panel in Table 4 displays the main implications of the mixture model. The mixture model suggests that about $80 \%$ of sampled population falls into the low-use category with an average of 1.6 visits, and the remaining $20 \%$ of the sample fall into the high-use category with an average of 3.8 visits. The mixture estimates for hospital care weeks are less precise and less reliable, but they also suggest that $87.4 \%$ of sample consist of low-users with an average stay of 0.3 weeks but for the remaining $12.6 \%$ the average stay is more than 2.5 weeks. The latter estimate unfortunately has a high standard error. This lack of precision in part may be due to the frequency distribution of hospital weeks being heavily 
skewed and concentrated at a few values, By contrast, the distribution of doctor visits is more spread out.

\subsection{Socioeconomic effects}

We now consider the equity issues via a more detailed look at the implications of the estimates from our preferred model. The discussion of these effects is somewhat imprecise because it is not clear exactly how some of these variables, e.g. family size or living in a big city, are related to income level, which is the variable of central interest. We also comment on the differences between these and other estimates from the two-part model.

\subsubsection{Physician visits}

The covariates income, full-time work status, and family size have significant effects on low-mean (infrequent) users but not on the high-mean (frequent) users. This can be rationalized by attributing high usage to poor health status, with other variables playing a small or negligible role. In the case of infrequent users income (INC3-4) and full-time work status have a positive impact $(p<0.10)$ while FAMSIZE has a negative impact $(p<0.05)$. The effect of living in larger cities (BIGCITY) is positive among infrequent users $(p<0.05)$ and is also positive among frequent users (close to significance at the 10\% level). The male gender effect (MALE) is negative among infrequent users $(p<0.01)$ but negligible among frequent users. The effect of age (AGE3-4; 45 years and older) is negative among frequent users $(p<0.10)$ but also negligible for infrequent users. The effects of the remaining variables: MARRIED, EDUCATION, DSATIS and SMALLCITY, 
are insignificant factors both among infrequent and among frequent users.

\subsubsection{Hospital care weeks}

We now consider the impact of income, being married or being a cohabitant, education and urban life on the low-mean users. The effect of income (INC3-4) is positive $(p<0.05)$, while the effect of being married (MARRIED), educated (EDUCYEAR) and living in larger cities (BIGCITY) is negative. Among frequent users education has a positive impact on usage. Family size (FAMSIZE) and working full-time (WORKING) have negative effects among frequent users $(p<$ 0.05). The effects of the dummy for people who perceive that their daily life is a source of satisfaction is negative among infrequent users $(p<0.10)$. Also for care weeks, the effect of being male (MALES) is negative among infrequent users $(p<0.01)$. However, the effect is positive among frequent users $(p<0.01)$. The pattern of age-effects is very irregular; AGE2 (35 - 44 years) has positive impact on infrequent users $(p<0.01)$ but negative among frequent users $(p<0.01)$. The

effect of AGE3 (45 - 64 years) is negative among infrequent users $(p<0.01)$ but positive among frequent users $(p<0.10)$. AGE4 $(65-76$ years $)$ is insignificant for both classes. People living in larger cities have fewer care weeks among infrequent users $(p<0.10)$ and also among frequent users (but is not significant). The SMALLCITY effect is also insignificant for both infrequent and frequent users.

\section{Discussion and conclusions}

The 2-component mixture model provides a better fit to the data for both physician visits and hospital care weeks than the two-part model, and it is easier to 
interpret. The results, however, are mixed in regard to the equity hypothesis. Although we find a significant income effect on physician visits this is confined only to low-mean, infrequent users in the third and fourth quintiles of the income distribution. For care weeks in hospital, we also find higher use for those in the third and fourth quintiles of the income distribution among infrequent users; but again no income effect is present among frequent users.

Among other socioeconomic factors education is a interesting factor. Again, however, the interpretation of the impact is complicated. Among the low-users, the more highly educated people use less hospital care weeks. This finding may be consistent with Grossman's (1972) observation that those with higher incomes are more efficient producers of health capital and that less health care is needed to reach a given level of health capital. However, among the high-users the effect of education is positive which is contrary to Grossman's hypothesis.

It is interesting also to compare our results with those presented by Gerdtham (1997) to see the implications of the 2-component mixture model. In the Gerdtham study, a positive income effect was found on the probability of doctors visits and hospital care weeks but no such effect was found on number of visits though a negative income effect was found on the number of care weeks. The current study finds similar results for doctors visits, i.e. a positive income effect among low users and no income effect on high users. However in regard of hospital care we find a positive income effect among low users and no income effect among high users. This difference in results probably reflects the absence of the latent class distinction and the consequent aggregation across heterogeneous groups with different behavior patterns. This nonrejection of the hypothesis of zero effect of 
income among high users of hospital care is also intuitively more reasonable than the negative income effect of the two-part model. Another difference between the two studies is that Gerdtham did not find any evidence of an education effect, whereas the current article finds a "mixed" effect that was described above. One final difference between the studies concerns the effect of urban life. Gerdtham found no effect on the probability of a physician visit but a positive effect on number of visits. This finding may be indicative for supplier induced demand in ambulatory care which may be difficult to justify in regard of the public health system. The current article on the other hand finds a positive effect of urban life both among low users (significant) and high users (almost significant) which may reflect lower costs of seeking care for individuals living in urbanized areas.

One limitation of this study is the questionable assumption that all covariates are exogenous. It is possible that self-assessed health status may depend upon the amount of health care consumed. A second limitation is the omission of some relevant variables that might provide a more refined measure of individual health status. In the absence of variables such as health awareness or health consciousness, which are plausibly correlated with income, positive income effects might simply act as proxies for the omitted variables. This again gives reason for exercising caution in interpreting income effects as indicating reduced access to health care by those with lower incomes. 


\section{References}

Cameron, A.C. and Trivedi, P.K. (1990), Regression based tests of overdispersion in the Poisson model. Journal of Econometrics 46, 255-274.

Deb, P., and P.K. Trivedi (1997), Demand for Medical Care by the Elderly in the United States: A Finite Mixture Approach, Journal of Applied Econometrics 12, 313-336.

Deb, P. and Trivedi, P.K. (1999), The Structure of Demand for Health Care: Latent Class versus Two-part Models, Working Paper, November 1999.

Gerdtham, U-G. (1997), Equity in health care utilisation: further evidence based on hurdle models and Swedish micro data, Health Economics 6, 303-319.

Grossman, M. (1972), On the concept of health capital and the demand for health, Journal of Political Economy 80, 223-255.

Grottendorst, P.V. (1995), A comparison of alternative models of prescription drug utilization, Health Economics 4, 183-198.

Hamilton, V.H., Merrigan, P. and Dufresne, E. (1997), Down and out: estimating the relationship between mental health and unemployment, Health Economics 6, 397-406.

Heckman, J. and B. Singer (1984), A Method of Minimizing the Impact of Distributional Assumptions in Econometric Models for Duration Data, Econometrica 52, 271-320.

Kakwani, N. Wagstaff, A. and van Doorslaer, E. (1997), Socioeconomic inequality in health: measurement, computation and statistical inference, Journal of Econometrics 77, 87-104.

Keeler, E.B., Manning, W.G. and Wells, K.B. (1988), The demand for episodes of menatl health services, Journal of Health Economics 7, 337-367.

Laird, N. (1978), Nonparametric Maximum Likelihood Estimation of a Mixing Distribution, Journal of the American Statistical Association 73, 805-811.

Manning, W.G., Morris, C.N., Newhouse, J.P. et al. (1981), A two-part model of the 
demand for medical care: preliminary results from the Health Insurance Study. In: van der Gaag, J, and Perlman, M, editors. Health, Economics, and Health Economics. Amsterdam: North-Holland, 103-123.

Mullahy, J. (1986), Specification and testing of some modified count data models. Journal of Econometrics 33, 341-365.

O'Donnell, O. and Propper, C. (1991), Equity and the distribution of UK National Health Service resources. Journal of Health Economics 10, 1-20.

Pohlmeier, W. and Ulrich, V. (1995), An econometric model of the two-part decision making process in the demand for health care. The Journal of Human Resources 30, 339-361.

Van Doorslaer, E. and Wagstaff, A. (1992), Equity in the delivery of health care: some international comparisons, Journal of Health Economics 11, 389-411.

Van Doorslaer, E., et al. (1999), Equity in the delivery of health care: further international comparisons, forthcoming in Journal of Health Economics.

Wagstaff, A., Doorslaer, E. van. and Paci, P. (1991), On the measurement of horisontal equity in the delivery of health care. Journal of Health Economics 10, 169-205.

Wagstaff, A. and van Doorslaer, E. (1998), Equity in health care finance and delivery, forthcoming in North Holland Handbook of Health Economics (eds.), A.J. Culyer and J.P. Newhouse. 


\section{TABLES}

Table 1: Physian visits and hospital care weeks: variable definitions and summary statistics. Number of observations $=5,011$.

\begin{tabular}{|c|c|c|c|}
\hline \multirow{2}{*}{\multicolumn{4}{|c|}{$\begin{array}{l}\text { Variable } \\
\text { Dependent } \\
\text { variables: }\end{array}$}} \\
\hline & & & \\
\hline VISITS & $=$ Number of visits per year & 2.0595 & 3.7187 \\
\hline HOSPWEEK & $=$ Number of hospital care weeks per year & 0.2971 & 2.2617 \\
\hline $\begin{array}{l}\text { Independent } \\
\text { variables: }\end{array}$ & & & \\
\hline MALE & $=1$ if male & 0.5053 & 0.5000 \\
\hline AGE2 & $=1$ if age is $35-44$ years & 0.3913 & 0.4881 \\
\hline AGE3 & $=1$ if age is $45-64$ years & 0.3225 & 0.4675 \\
\hline AGE4 & $=1$ if age is $65-76$ years & 0.1507 & 0.3578 \\
\hline BADHLTH & $=1$ if self assessed health is "poor health" & 0.0421 & 0.2009 \\
\hline FAIRHLTH & $=1$ if self assessed health is "fair health" & 0.1838 & 0.3874 \\
\hline LCHRONIC & $\begin{array}{l}=1 \text { if chronic illness but able to run a shorter } \\
\text { distance and climb stairs without a problem }\end{array}$ & 0.0834 & 0.2765 \\
\hline NLCHRONIC & $\begin{array}{l}=1 \text { if chronic illness and unable to run a shorter } \\
\text { distance and climb stairs without a problem }\end{array}$ & 0.0760 & 0.2651 \\
\hline MARRIED & $=1$ if the individual is married or cohabiting & 0.6566 & 0.4749 \\
\hline FAMSIZE & $=$ Number of persons in the houshold & 2.6230 & 1.3423 \\
\hline WORKING & $=1$ if currently working full-time & 0.5578 & 0.4967 \\
\hline EDUCYEAR & $=$ Years of formal schooling & 10.8966 & 3.3908 \\
\hline $\mathrm{INC} 2$ & $\begin{array}{l}=1 \text { if the disposable annual household income is } \\
\text { in the second quartile of the income distribution }\end{array}$ & 0.2000 & 0.4000 \\
\hline INC3 & $\begin{array}{l}=1 \text { if the disposable annual household income is } \\
\text { in the third quartile of the income distribution }\end{array}$ & 0.1996 & 0.3997 \\
\hline INC4 & $\begin{array}{l}=1 \text { if the disposable annual household income is } \\
\text { in the fourth quartile of the income distribution }\end{array}$ & 0.2016 & 0.4012 \\
\hline INC5 & $\begin{array}{l}=1 \text { if the disposable annual household income is } \\
\text { in the fifth quartile of the income distribution }\end{array}$ & 0.2010 & 0.4008 \\
\hline DSATIS & $\begin{array}{l}=1 \text { if daily life is a source of personal } \\
\text { satisfaction }\end{array}$ & 0.5853 & 0.4927 \\
\hline BIGCITY & $\begin{array}{l}=1 \text { if the individual lives in Stockholm, } \\
\text { Gothenburg or Malmö }\end{array}$ & 0.2742 & 0.4462 \\
\hline SMALLCITY & $\begin{array}{l}=1 \text { if the individual lives in cities larger than } \\
30,000 \text { inhabitants }\end{array}$ & 0.2241 & 0.4170 \\
\hline
\end{tabular}


Table 2: Estimation results: Dependent variable: Frequency of physisican visit (Covariates included).

\begin{tabular}{lcccc}
\hline \hline Covariates & \multicolumn{2}{c}{ Two-part Negbin2 } & \multicolumn{2}{c}{ Finite mixture Negbin2 } \\
& $\begin{array}{c}\text { Users/Nonusers } \\
\text { Coefficients } \\
\text { (t-values) }\end{array}$ & $\begin{array}{c}\text { Conditional Users } \\
\text { Coefficients } \\
\text { (t-values) }\end{array}$ & $\begin{array}{c}\text { Infrequent Users } \\
\text { Coefficients } \\
\text { (t-values) }\end{array}$ & $\begin{array}{c}\text { Frequent Users } \\
\text { Coefficients } \\
\text { (t-values }\end{array}$ \\
\hline ONE & 0.274 & $0.344^{*}$ & -0.018 & $1.330^{* *}$ \\
MALE & {$[1.535]$} & {$[1.686]$} & {$[-0.102]$} & {$[2.471]$} \\
& $-0.421^{* * *}$ & -0.092 & $-0.372^{* * *}$ & 0.031 \\
AGE2 & {$[-6.618]$} & {$[-1.396]$} & {$[-6.697]$} & {$[0.222]$} \\
& $-0.195^{*}$ & 0.072 & -0.070 & -0.004 \\
AGE3 & {$[-1.753]$} & {$[0.574]$} & {$[-0.740]$} & {$[-0.018]$} \\
& $-0.304^{* *}$ & -0.191 & -0.136 & $-0.413^{*}$ \\
AGE4 & {$[-2.487]$} & {$[-1.463]$} & {$[-1.284]$} & {$[-1.793]$} \\
& 0.036 & $-0.336^{* *}$ & -0.001 & $-0.543^{*}$ \\
BADHLTH & {$[0.237]$} & {$[-2.073]$} & {$[-0.005]$} & {$[-1.811]$} \\
& $1.726^{* * *}$ & $1.178^{* * *}$ & $1.267^{* * *}$ & $1.065^{* * * *}$ \\
FAIRHLTH & {$[6.004]$} & {$[9.201]$} & {$[10.886]$} & {$[3.787]$} \\
& $1.007^{* * *}$ & $0.870^{* * *}$ & $0.814^{* * *}$ & $0.928^{* * *}$ \\
LCHRONIC & {$[10.248]$} & {$[11.402]$} & {$[10.553]$} & {$[6.844]$} \\
& $1.067^{* * *}$ & $0.728^{* * *}$ & $0.744^{* * *}$ & $0.747^{* * *}$ \\
NLCHRONIC & {$[6.020]$} & {$[7.620]$} & {$[8.398]$} & {$[4.371]$} \\
& $1.235^{* * *}$ & $0.597^{* * *}$ & $0.796^{* * *}$ & $0.629^{* * *}$ \\
MARRIED & {$[8.270]$} & {$[6.960]$} & {$[10.445]$} & {$[3.701]$} \\
& 0.129 & $-0.257^{* * *}$ & -0.066 & -0.111 \\
FAMSIZE & {$[1.187]$} & {$[-2.671]$} & {$[-0.732]$} & {$[-0.701]$} \\
& $-0.068^{* *}$ & -0.041 & $-0.068^{* *}$ & -0.042 \\
WORKING & {$[-2.354]$} & {$[-1.261]$} & {$[-2.348]$} & {$[-0.848]$} \\
& $0.192^{* *}$ & -0.054 & $0.143^{* *}$ & -0.137 \\
EDUCYEAR & {$[2.550]$} & {$[-0.661]$} & {$[2.235]$} & {$[-0.962]$} \\
& 0.012 & -0.001 & 0.014 & -0.010 \\
& {$[1.146]$} & {$[-0.103]$} & {$[1.222]$} & {$[-0.503]$} \\
\hline & & & &
\end{tabular}


Table 2: Continued.

\begin{tabular}{|c|c|c|c|c|}
\hline \multirow[t]{2}{*}{ Covariates } & \multicolumn{2}{|c|}{ Two-part Negbin2 } & \multicolumn{2}{|c|}{ Finite mixture Negbin2 } \\
\hline & $\begin{array}{l}\text { Users/Nonusers } \\
\text { Coefficients } \\
\text { (t-values) }\end{array}$ & $\begin{array}{c}\text { Conditional Users } \\
\text { Coefficients } \\
\text { (t-values) }\end{array}$ & $\begin{array}{c}\text { Infrequent Users } \\
\text { Coefficients } \\
\text { (t-values) }\end{array}$ & $\begin{array}{l}\text { Frequent Users } \\
\text { Coefficients } \\
\text { (t-values }\end{array}$ \\
\hline \multirow[t]{2}{*}{$\overline{\mathrm{INC} 2}$} & -0.014 & -0.069 & 0.033 & -0.107 \\
\hline & {$[-0.124]$} & {$[-0.711]$} & {$[0.360]$} & {$[-0.641]$} \\
\hline \multirow[t]{2}{*}{ INC3 } & 0.139 & 0.059 & $0.191^{*}$ & -0.041 \\
\hline & {$[1.090]$} & {$[0.534]$} & {$[1.762]$} & {$[-0.218]$} \\
\hline \multirow[t]{2}{*}{$\mathrm{INC} 4$} & 0.167 & 0.163 & $0.282^{* *}$ & -0.004 \\
\hline & {$[1.175]$} & [1.328] & {$[2.354]$} & {$[-0.022]$} \\
\hline \multirow[t]{2}{*}{ INC5 } & 0.028 & 0.205 & 0.174 & 0.098 \\
\hline & {$[0.188]$} & {$[1.516]$} & [1.388] & {$[0.459]$} \\
\hline \multirow[t]{2}{*}{ DSATIS } & -0.039 & 0.054 & -0.010 & 0.062 \\
\hline & {$[-0.607]$} & {$[0.842]$} & {$[-0.201]$} & {$[0.534]$} \\
\hline \multirow[t]{2}{*}{ BIGCITY } & 0.098 & $0.184^{* *}$ & $0.135^{* *}$ & 0.216 \\
\hline & [1.314] & {$[2.419]$} & {$[2.295]$} & {$[1.623]$} \\
\hline \multirow[t]{2}{*}{ SMALLCITY } & 0.043 & -0.000 & 0.061 & -0.027 \\
\hline & {$[0.552]$} & {$[-0.005]$} & {$[0.967]$} & {$[-0.213]$} \\
\hline \multirow[t]{2}{*}{$\alpha$} & & 1.649 & 0.538 & 1.529 \\
\hline & & {$[7.452]$} & {$[3.275]$} & {$[2.539]$} \\
\hline \multirow[t]{2}{*}{$\pi$} & & - & 0.792 & \\
\hline & & & [6.124] & \\
\hline -Log-lik & & 8957.216 & & 8903.172 \\
\hline AIC & & 17996.42 & & 17892.34 \\
\hline $\mathrm{BIC}$ & & 18263.71 & & 18172.67 \\
\hline
\end{tabular}

Note: The t-statistics are based on robust estimates of standard errors. 
Table 3: Estimation results: Dependent variable: Frequency of care week in hospital (Covariates included).

\begin{tabular}{lcccc}
\hline \hline Covariates & \multicolumn{2}{c}{ Two-part Negbin2 } & \multicolumn{2}{c}{ Finite mixture Negbin2 } \\
& $\begin{array}{c}\text { Users/Nonusers } \\
\text { Coefficients } \\
\text { (t-values) }\end{array}$ & $\begin{array}{c}\text { Conditional Users } \\
\text { Coefficients } \\
\text { (t-values) }\end{array}$ & $\begin{array}{c}\text { Infequent Users } \\
\text { Coefficients } \\
\text { (t-values) }\end{array}$ & $\begin{array}{c}\text { Frequent Users } \\
\text { Coefficients } \\
\text { (t-values }\end{array}$ \\
\hline ONE & $-2.678^{* * *}$ & $-5.025^{* * *}$ & $-1.268^{*}$ & -1.910 \\
MALE & {$[-8.061]$} & {$[-4.580]$} & {$[-1.660]$} & {$[-1.590]$} \\
& $-0.205^{*}$ & -0.211 & $-0.844^{* * *}$ & $2.052^{* * * *}$ \\
AGE2 & {$[-1.834]$} & {$[-0.742]$} & {$[-3.371]$} & {$[4.900]$} \\
& 0.136 & 0.361 & $0.865^{* * *}$ & -4.213 \\
AGE3 & {$[0.611]$} & {$[0.620]$} & {$[2.615]$} & {$[-3.688]$} \\
& $-0.495^{* *}$ & 0.991 & $-0.751^{*}$ & $1.726^{*}$ \\
AGE4 & {$[-2.042]$} & {$[1.524]$} & {$[-1.921]$} & {$[1.760]$} \\
& 0.102 & 0.606 & 0.361 & -0.474 \\
BADHLTH & {$[0.389]$} & {$[0.895]$} & {$[0.811]$} & {$[-0.609]$} \\
& $1.588^{* * *}$ & $1.551^{* * *}$ & $3.063^{* * *}$ & 1.095 \\
FAIRHLTH & {$[7.234]$} & {$[3.913]$} & {$[9.201]$} & {$[1.257]$} \\
& $0.728^{* * *}$ & $0.909^{* * *}$ & $1.054^{* * *}$ & $1.445^{* * *}$ \\
LCHRONIC & {$[5.247]$} & {$[2.400]$} & {$[4.737]$} & {$[3.298]$} \\
& $0.984^{* * *}$ & 0.249 & $1.176^{* * *}$ & 0.399 \\
NLCHRONIC & {$[5.609]$} & {$[0.755]$} & {$[4.439]$} & {$[0.621]$} \\
& $0.675^{* * *}$ & -0.441 & $0.596^{* * *}$ & 0.475 \\
MARRIED & {$[3.857]$} & {$[-1.084]$} & {$[2.564]$} & {$[0.866]$} \\
& $-0.317^{*}$ & 0.510 & $-0.534^{*}$ & -0.653 \\
FAMSIZE & {$[-1.780]$} & {$[0.933]$} & {$[-1.659]$} & {$[-0.999]$} \\
& -0.065 & -0.117 & -0.056 & $-1.331^{* * *}$ \\
WORKING & {$[-1.260]$} & {$[-0.602]$} & {$[-0.601]$} & {$[-3.690]$} \\
& -0.186 & -0.006 & -0.094 & $-2.463^{* *}$ \\
EDUCYEAR & {$[-1.331]$} & {$[-0.016]$} & {$[-0.326]$} & {$[-4.681]$} \\
& -0.001 & 0.010 & $-0.085^{*}$ & $0.291^{* * *}$ \\
& {$[-0.058]$} & {$[0.248]$} & {$[-1.901]$} & {$[3.280]$} \\
\hline & & & &
\end{tabular}


Table 3: Continued.

\begin{tabular}{|c|c|c|c|c|}
\hline \multirow[t]{2}{*}{ Covariates } & \multicolumn{2}{|c|}{ Two-part Negbin2 } & \multicolumn{2}{|c|}{ Finite mixture Negbin2 } \\
\hline & $\begin{array}{c}\text { Users/Nonusers } \\
\text { Coefficients } \\
\text { (t-values) }\end{array}$ & $\begin{array}{c}\text { Conditional Users } \\
\text { Coefficients } \\
\text { (t-values) }\end{array}$ & $\begin{array}{c}\text { Infrequent Users } \\
\text { Coefficients } \\
\text { (t-values) }\end{array}$ & $\begin{array}{c}\text { Frequent Users } \\
\text { Coefficients } \\
\text { (t-values }\end{array}$ \\
\hline \multirow[t]{2}{*}{ INC2 } & 0.271 & $-0.995^{*}$ & -0.204 & 0.765 \\
\hline & {$[1.424]$} & {$[-1.834]$} & {$[-0.553]$} & {$[1.565]$} \\
\hline \multirow[t]{2}{*}{ INC3 } & $0.925^{* * *}$ & $-1.440^{* *}$ & $1.035^{* * *}$ & -0.220 \\
\hline & {$[4.174]$} & {$[-2.332]$} & {$[2.947]$} & {$[-0.303]$} \\
\hline \multirow[t]{2}{*}{ INC4 } & $0.839^{* * *}$ & $-1.819^{* *}$ & $0.844^{* *}$ & -0.672 \\
\hline & {$[3.311]$} & {$[-2.484]$} & {$[2.013]$} & {$[-0.717]$} \\
\hline \multirow[t]{2}{*}{ INC5 } & $0.827^{* * *}$ & $-1.831^{* *}$ & 0.615 & -0.045 \\
\hline & {$[2.973]$} & {$[-2.245]$} & {$[1.380]$} & {$[-0.063]$} \\
\hline \multirow[t]{2}{*}{ DSATIS } & -0.037 & $-0.512^{*}$ & $-0.292^{*}$ & -0.015 \\
\hline & {$[-0.346]$} & {$[-1.756]$} & {$[-1.938]$} & {$[-0.039]$} \\
\hline \multirow[t]{2}{*}{ BIGCITY } & $-0.262^{* *}$ & $0.559^{*}$ & $-0.346^{*}$ & -0.608 \\
\hline & {$[-1.986]$} & {$[-1.858]$} & {$[-1.873]$} & {$[-1.439]$} \\
\hline \multirow[t]{2}{*}{ SMALLCITY } & -0.176 & 0.028 & -0.142 & -0.580 \\
\hline & {$[-1.272]$} & {$[0.072]$} & {$[0.712]$} & {$[-1.362]$} \\
\hline \multirow[t]{2}{*}{$\alpha$} & & 1111.363 & 8.261 & 5.806 \\
\hline & & {$[1.259]$} & [5.818] & [0.933] \\
\hline$\pi$ & & - & $\begin{array}{l}0.874 \\
{[5.921]}\end{array}$ & \\
\hline -Log-lik & & 2048.346 & & 2039.02 \\
\hline $\mathrm{AIC}$ & & 4178.68 & & 4109.58 \\
\hline $\mathrm{BIC}$ & & 4527.97 & & 4475.91 \\
\hline
\end{tabular}

Note: The t-statistics are based on robust standard errors. 
Table 4A: Comaprison of Actual and Fitted Frequencies

\begin{tabular}{|c|c|c|c|c|c|c|c|c|c|c|}
\hline \multicolumn{11}{|c|}{ Actual and Fitted Relative Frequencies (\%) } \\
\hline Number of Physician Visits & 0 & 1 & 2 & 3 & 4 & 5 & 6 & 7 & 8 & $>8$ \\
\hline Observed & 38.8 & 21.9 & 14.6 & 7.6 & 5.0 & 3.7 & 2.3 & 1.1 & 0.7 & 4.3 \\
\hline Fitted: Mixture & 37.8 & 24.2 & 13.7 & 7.8 & 4.64 & 2.95 & 2.0 & 1.41 & 1.04 & 4.46 \\
\hline Fitted: TPM & 38.7 & 23.1 & 12.7 & 7.66 & 4.89 & 3.25 & 2.24 & 1.59 & 1.15 & 4.72 \\
\hline \multicolumn{11}{|c|}{ Actual and Fitted Relative Frequencies (\%) } \\
\hline Number of Hospital Care Weeks & 0 & 1 & 2 & 3 & 4 & 5 & 6 & 7 & $>7$ & \\
\hline Observed & 91.7 & 5 & 1.5 & 1.5 & 0.5 & 0.5 & 0.10 & 0.1 & 0.8 & \\
\hline Fitted: Mixture & 91.4 & 4.57 & 1.44 & 0.67 & 0.39 & 0.25 & 0.17 & 0.13 & 0.92 & \\
\hline Fitted: TPM & 91.3 & 4.33 & 1.56 & 0.79 & 0.47 & 0.30 & 0.21 & 0.15 & 0.89 & \\
\hline
\end{tabular}

Table 4B: Comparison of Empirical Moments of the Mixture Components

\begin{tabular}{|c|c|c|c|}
\hline$\overline{\text { Variable }}$ & $\begin{array}{l}\text { Frequent Users } \\
\text { Mean (St.Dev.) }\end{array}$ & $\begin{array}{l}\text { Infrequent Users } \\
\text { Mean (St. Dev.) }\end{array}$ & $\begin{array}{l}\text { All users } \\
\text { Mean (St. Dev.) }\end{array}$ \\
\hline Doctor Visits & 3.877 (2.981) & 1.598 (1.413) & $2.071 \quad(1.693)$ \\
\hline Hospital care weeks & $2.534(37.82)$ & $0.329(1.259)$ & $0.607(4.891)$ \\
\hline
\end{tabular}

